\title{
S100A4 protects mice from high-fat diet-induced obesity and inflammation
}

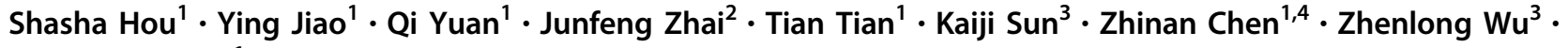 \\ Jinhua Zhang $\mathbb{1}^{1}$
}

Received: 10 February 2018 / Revised: 3 April 2018 / Accepted: 10 April 2018 / Published online: 22 May 2018

(c) United States \& Canadian Academy of Pathology 2018

\begin{abstract}
As a member from S100 calcium-binding protein family, S100A4 is ubiquitous and elevated in tumor progression and metastasis, but its role in regulating obesity has not been well characterized. In this study, we showed that S100A4 was mainly expressed by stromal cells in adipose tissue and the S100A4 level in adipose tissue was decreased after high-fat diet (HFD). S100A4 deficient mice exhibited aggravated symptoms of obesity and suppressed insulin signaling after 12 weeks of HFD. Aggravated obesity in S100A4 deficient mice were found to be positively correlated with higher inflammatory status of the liver. Then, we found that extracellular S100A4 or overexpressed S100A4 inhibited adipogenesis and decreased mRNA levels of inflammation gene in 3T3-L1 adipocytes in vitro; whereas small interfering RNA (siRNA)-mediated suppression of S100A4 displayed the opposite results. Additionally, the protective effect induced by S100A4 during HFDinduced obesity was tightly related with activation of Akt signaling in adipose tissues, as well as livers and muscles. Taken together, we demonstrate that S100A4 is an inhibitory factor for obesity and attenuates the inflammatory reaction, while activating the Akt signaling, which suggest that S100A4 is a potential candidate for the treatment of diet-induced obesity and its complications.
\end{abstract}

\section{Introduction}

Obesity is an international healthcare priority due to its increasing prevalence and its association with type 2 diabetes (T2D) [1]. Excessive energy intake and metabolism disequilibrium lead to the excessive accumulation of fat,

Electronic supplementary material The online version of this article (https://doi.org/10.1038/s41374-018-0067-y) contains supplementary material, which is available to authorized users.

Jinhua Zhang

zhangjh@bjtu.edu.cn

1 The College of Life Science and Bioengineering, Beijing Jiaotong University, No.3 Shangyuancun Road, Beijing, P.R. China

2 The Chinese Academy of Inspection and Quarantine, Beijing, P. R. China

3 The State Key Laboratory of Animal Nutrition, College of Animal Science and Technology, China Agricultural University, Beijing, P. R. China

4 The Cell Engineering Research Center and Department of Cell Biology, State Key Laboratory of Cancer, Fourth Military Medical University, Xi'an, P. R. China which is deemed as the major cause driving of obesity development $[2,3]$. Notably, inhibited insulin signaling of target tissues, including adipose tissue, occurs at the onset of metabolic diseases [4, 5].

Disturbed insulin pathway has been established as one of the main pathogenic factors for adiposity and its complications [6, 7]. Fasting hyperglycemia, due to increased rates of hepatic gluconeogenesis, and the inability of insulin to suppress this process are the hallmark of obesity-related T2D [8, 9]. Multiple factors contribute to the obesity-related insulin signaling inactivation, which is caused by a high-fat diet (HFD), including inflammatory factors and unbalanced adipokines [10-12]. Expounding the underlying mechanisms at the interface between adiposity and insulin pathway counts a great deal in searching for novel therapeutic approaches for obesity and its complications.

S100A4, also known as fibroblast-specific protein 1, is a member of the S100 calcium-binding protein family and was first cloned in metastatic cells and fibroblasts $[13,14]$. It is expressed in various cell types, including fibroblasts, macrophages and tumor cells [15-20]. S100A4 was reported to be intracellular, or secreted as a normal cytokine, and it plays important roles in tumor cell survival and metastasis 
$[19,21,22]$. In addition, it is also involved in a wide range of biological functions, such as fibrogenesis and particularly inflammation regulation [16, 23, 24]. Previous studies have shown that S100A4 stimulated the releasing of various cytokines and growth factors that favors the inflammation process [25]. On the other hand, inflammation state in tissues was tightly associated with the HFD-induced obesity and obesity-related metabolic syndromes [26, 27]. However, the specific role of the S100A4 protein in obesity development and obesity-related inflammation has not been well identified. In this study, we showed that S100A4 was mainly expressed by stromal cells in adipose tissue and protected mice from HFD-induced obesity and glucose intolerance. Furthermore, S100A4 deficiency aggravated hepatic lipid accumulation and inflammation, and both extracellular and endogenous S100A4 promoted insulin signaling activation. Thus, S100A4 may represent a potential candidate for the treatment and prevention of dietinduced obesity and insulin resistance.

\section{Materials and methods}

\section{Mice, diet, and treatments}

C57BL/6 mice (wild type (WT)) were obtained from Vital River (Beijing, China). S100A4 knockout mice (S100A4 ${ }^{-1-}$ ) on C57BL/6 background were purchased from the Jackson Laboratory in the United States (Bar Harbor, ME, USA). The mice were all male and 6-week-old before the diets administration. All mice were bred under specific pathogen-free conditions in the animal facilities at the Institute of Biophysics, Chinese Academy of Sciences. All animal studies were performed after being approved by the Institutional Laboratory Animal Care and Use Committee. Half of the mice were fed a control diet (CD, 10\% of total energy from fat, Trophic, Nantong, China) and half of mice were fed an HFD (60\% of total energy from fat, Supplementary Table 1) to induce obesity. Mice were fed a CD or an HFD for 12 weeks. Twelve weeks after HFD, all mice were sacrificed. At necropsy, the abdominal fat (retroperitoneal) of mice were carefully excised and weighed.

\section{Metabolic measurements}

For the glucose tolerance test (GTT), blood samples were obtained at $0,15,30,60$, and $120 \mathrm{~min}$ after intraperitoneal injection of $2 \mathrm{~g} / \mathrm{kg}$ dextrose. Insulin tolerance tests (ITTs) were performed by injecting $1 \mathrm{U} / \mathrm{kg}$ regular insulin (Sigma, St Louis, MO, USA) intraperitoneally, followed by blood collection at $0,15,30,60$, and $120 \mathrm{~min}$. Blood glucose values were determined using Accu-Chek Performa glucometer (Roche, Basel, Switzerland). Serum cholesterol
(CHO) and triglycerides (TGs) were assayed by the Department of Hematology in Animal Hospital of China Agricultural University.

\section{Histology and immunostaining}

Cryostat sections from white adipose tissues (WATs) and liver tissues were prepared. Five micrometer-thick sections were stained with H\&E for histological analysis or Oil Red $\mathrm{O}$ for the fat droplets accumulation.

For immunohistochemistry (IHC) staining, cryostat sections were incubated with anti-S100A4 (Abcam, Cambridge, UK), anti-F4/80 (BD Pharmingen, San Diego, CA), and anti-Gr-1 antibodies (BD Pharmingen, San Diego, CA), respectively, then were incubated with species matched Alexa dye-labeled or horseradish peroxidase-conjugated secondary antibodies.

For fluorescence double staining, cryostat sections were incubated with anti-S100A4 (Abcam, Cambridge, UK), anti-F4/80 (BD Pharmingen, San Diego, CA), anti- $\alpha$-SMA (Abcam, Cambridge, UK) antibodies, followed by the staining with Alexa Fluor 488 or 555-conjugated secondary antibodies (Invitrogen, Carlsbad, CA, USA). Sections were evaluated under the microscope (DP71, OLYMPUS) for bright-field and fluorescence microscopy.

\section{Isolation of stromal cells from adipose tissues}

Adipose tissues were cut into small pieces and digested by enzyme mixture containing $1 \mathrm{mg} / \mathrm{ml}$ collagenase type 2 (Worthington, Lakewood, USA) and $0.1 \mathrm{mg} / \mathrm{ml}$ DNase I (Sigma, St Louis, MO, USA) for $40 \mathrm{~min}$ at $37^{\circ} \mathrm{C}$.

During digestion, released cells were collected on ice, and fresh enzyme mixture was added every $10 \mathrm{~min}$. With this method, adipose tissues were completely digested to release stromal cells, including fibroblasts. Released cells were spun down to separate stromal vascular fraction (SVF) cells from floating adipocytes. Then stromal cells were resuspended in complete Roswell Park Memorial Institute 1640 (RPMI 1640) medium containing 10\% fetal bovine serum (FBS) and filtered through a $70-\mu \mathrm{m}$ cell strainer.

\section{Cell culture and treatment}

Murine 3T3-L1 preadipocytes were a kind gift from Dr. Zhenlong Wu (College of Animal Science and Technology, China Agricultural University, China). 3T3-L1 preadipocytes were cultured in RPMI 1640 supplemented with $10 \% \mathrm{FBS}$ and $100 \mathrm{U} / \mathrm{ml}$ penicillin-streptomycin (Invitrogen, Carlasbad, CA, USA) in a humidified atmosphere containing $5 \% \quad \mathrm{CO}_{2}$ at $37^{\circ} \mathrm{C}$. Adipocyte differentiation was induced as follows: cells planted in RPMI 1640 containing 

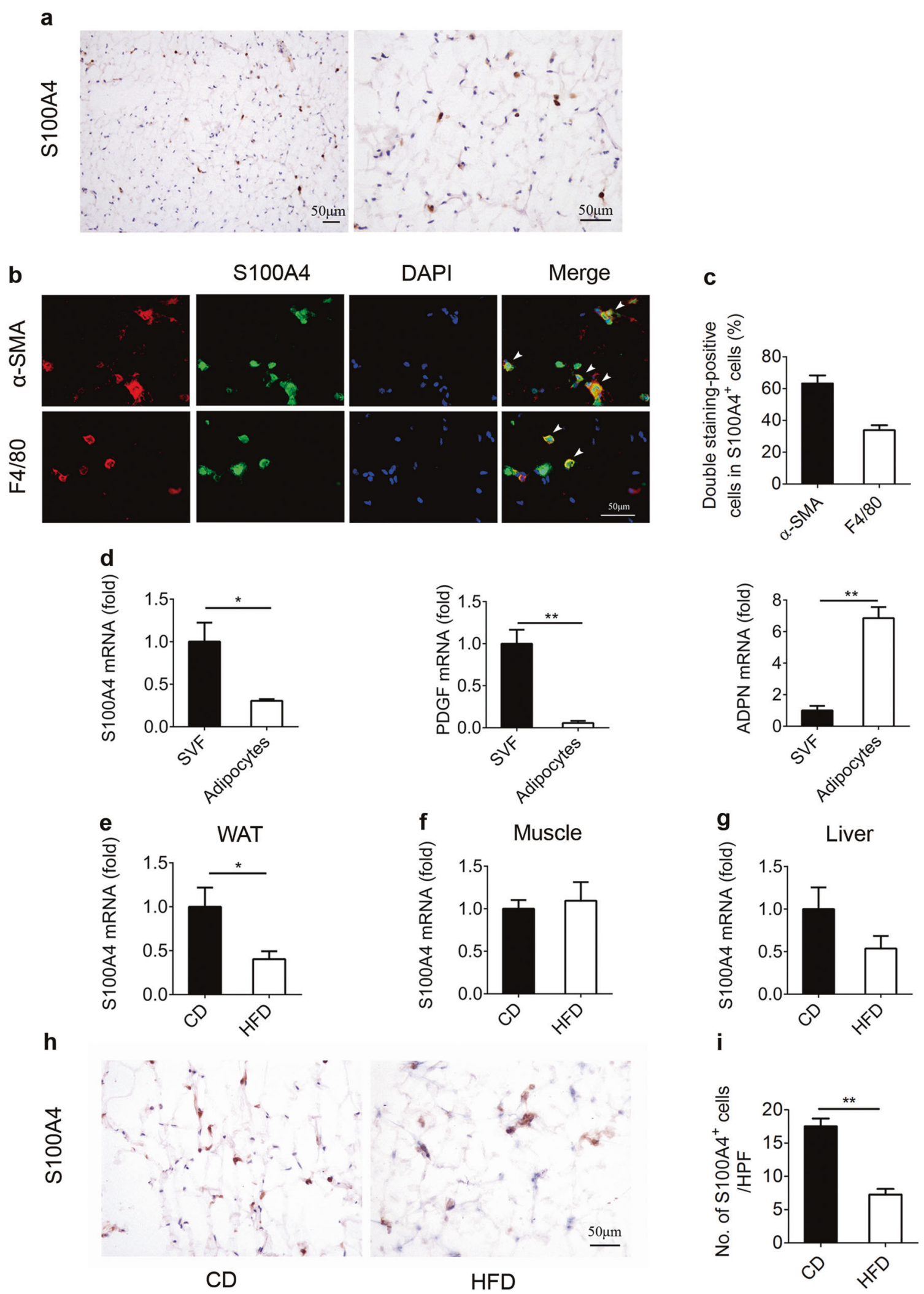

$10 \%$ FBS, $500 \mu \mathrm{M}$ 3-isobutyl-1-methylxanthine, $1 \mu \mathrm{g} / \mathrm{ml}$ insulin, and $1 \mathrm{mM}$ dexamethasone (Sigma, St Louis, MO, USA). After 2 days of incubation, the medium was replaced with RPMI 1640 containing 10\% FBS and $1 \mu \mathrm{g} / \mathrm{ml}$ insulin. Then, the cells were transferred to basic medium for another 2 days. 
Fig. $1 \mathrm{~S} 100 \mathrm{~A} 4$ is mainly expressed by fibroblasts and macrophages in adipose tissue, and it is downregulated in HFD-fed WT mice. Groups of $\mathrm{C} 57 \mathrm{BL} / 6$ mice and $\mathrm{S} 100 \mathrm{~A} 4^{-1-}$ mice were fed a CD or HFD for 12 weeks. a S100A4 staining of WAT sections from WT mice $(n=3$ per group). Scale bar, $50 \mu \mathrm{m}$. b Double immunohistochemical staining of S100A4 (green) with $\alpha$-SMA (red) or F4/80 (red) in the WAT. Nuclei were counter-stained with DAPI (blue) ( $n=3$ per group). Scale bar, $50 \mu \mathrm{m}$. c The percentages of double staining positive cells in S100A4 $4^{+}$cells ( $n=3$ per group). d The mRNA levels of S100A4, PDGF (as a marker of SVF cells) and ADPN (as a marker of adipocytes) in SVF cells and adipocytes from adipose tissue of WT mice ( $n$ $=5$ per group). $\mathbf{e}-\mathbf{g}$ The mRNA levels of S100A4 in WATs, muscles and livers from WT mice fed with a CD or HFD ( $n=3$ per group). $\mathbf{h}$ S100A4 staining of WAT from WT mice fed with a CD or HFD $(n=3$ per group). $\mathbf{i}$ The numbers of S100A4 ${ }^{+}$cells of each high power field $(\mathrm{HPF})(\times 200)$ from WAT. CD normal chow diet, HFD high-fat diet. $* P<0.05, * * P<0.01$

\section{Quantitative real-time polymerase chain reaction (qPCR)}

Total cellular RNA was extracted from collected cells using the TRIzol reagent (Invitrogen, Carlsbad, CA, USA). We synthesized cDNA using a Prime Script RT Master Mix Kit (Takara, Tokyo, Japan). qPCR was performed in duplicate with a SYBR Premix Ex TaqTM Kit (Takara, Tokyo, Japan). The data were analyzed using the $2^{-\Delta \Delta C t}$ method and normalized against glyceraldehyde-3-phosphate dehydrogenase (GAPDH) expression.

\section{Cytokine analysis}

To detect multiple cytokines in the livers, tissues were homogenized in ice-cold phosphate buffer saline PBS. Homogenates were centrifuged at $12,000 \times g$ for $15 \mathrm{~min}$. The supernatant was collected, and the ProcartaPlex ${ }^{\mathrm{TM}}$ multiplex immunoassay (Luminex) (eBioscience, California, USA) was used on a Bioplex-200 system with the Bioplex Manger 5.0 software. The cytokines were analyzed according to the manufacturer's protocol.

\section{Western blot}

Cultured cells and dissected tissues were collected, and protein was extracted using RIPA lysis buffer (Beyotime, shanghai, China) supplemented with a cocktail protease inhibitor (Biotool, Huston, USA). Based on the protein concentrations measured using a BCA kit (Bio-Rad, Shanghai, China), equal amounts ( $30 \mu \mathrm{g})$ of samples were mixed with 5X SDS loading buffer (Beyotime, Shanghai, China) and $\mathrm{dd}_{2} \mathrm{O}$. Samples were heated at $99^{\circ} \mathrm{C}$ for $5 \mathrm{~min}$ and separated by electrophoresis on a 10\% SDS-PAGE gel at $115 \mathrm{~V}$ for $1.2 \mathrm{~h}$. Proteins were transferred to a PVDF membrane at $200 \mathrm{~mA}$ for $1 \mathrm{~h}$. Membranes were blocked in $5 \%$ milk of TBST at room temperature (RT) for $1 \mathrm{~h}$ and incubated overnight at $4{ }^{\circ} \mathrm{C}$ with the following primary antibodies: Akt, phospho-Akt (Ser473), and GAPDH (1:1000; Cell Signaling Technology, Danvers, MA, USA). Membranes were rinsed in TBST, incubated with appropriate secondary antibodies for $1 \mathrm{~h}$ at RT and then washed in 1X TBST. After incubation with the ECL plus system (Amersham Biosciences, Uppsala, Sweden), signals were detected using the Image Quant LAS 4000 mini system (GE Healthcare Bio-Sciences, Pittsburgh, PA, England).

\section{Recombinant vector transfection and small interfering RNA (siRNA) interference}

pEGFP and pEGFP-S100A4 plasmids were kindly provided by Dr. Yingjie Wu (College of Animal Science and Technology, China Agricultural University, China). Transfection of the vectors was performed using Lipofectamine 2000, according to the manufacturer's protocols (Invitrogen, 18292-011). S100A4 siRNA and a nonspecific negative control were purchased from Cell Signaling Technology (USA) and transfected using Lipofectamine 2000, according to the manufacturer's protocols.

\section{Statistics}

All of the data were expressed as the mean \pm SEM and analyzed using GraphPad Prism software. Significant differences between mean values were obtained using three independent experiments. Differences between two groups were compared using a two-tailed unpaired Student's $t$-test analysis. One-way ANOVA tests with a Bonferroni correction were used for multiple comparisons. $P<0.05$ was considered statistically significant.

\section{Results}

\section{S100A4 is expressed in adipose tissue and downregulated in HFD-fed WT mice}

The expression of S100A4 in adipose tissues is still not clear. In this study, $\mathrm{S} 100 \mathrm{~A} 4^{+}$cells in WAT were detected by IHC, and many $\mathrm{S} 100 \mathrm{~A}^{+}$cells were found in adipose tissues (Fig. 1a). Using double staining, we further revealed that most of the S100A4 ${ }^{+}$cells were fibroblasts and macrophages. Among these cells, about $63.4 \%$ of the S100A4 $4^{+}$ cells were $\alpha-\mathrm{SMA}^{+}$and $33.8 \%$ of the $\mathrm{S} 100 \mathrm{~A} 4^{+}$cells were $\mathrm{F} 4 / 80^{+}$(Fig. 1b, c), while the $\mathrm{S} 100 \mathrm{~A} 4^{+}$cells rarely expressed CD31, Gr-1, CD4, or CD8 (data not shown). Adipocytes can be separated from the SVF cells that contain the leukocytes and stromal cells after enzymatic digestion of adipose tissue [28]. We further analyzed S100A4 expression in WAT by qPCR and found that it was mainly 
Fig. 2 S100A4 deficiency aggravates HFD-induced obesity. a The body weights of WT and S100A4 $4^{-l-}$ mice fed with a CD or HFD were monitored weekly ( $n=9$ per group). b Abdominal fat weight of WT and S100A44 ${ }^{-l-}$ mice after 12 weeks of CD or HFD ( $n$ $=4$ per group). $\mathbf{c}$ H\&E staining of WAT of WT and S100A4 $4^{-l-}$ mice fed with $\mathrm{CD}$ or $\operatorname{HFD}(n=3$ per group). Scale bar, $50 \mu \mathrm{m} . * P$ $<0.05, * * P<0.01$

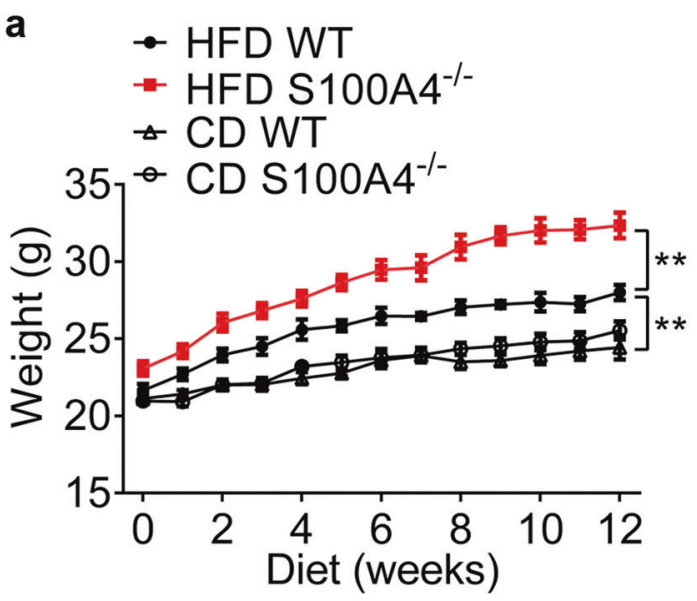

b

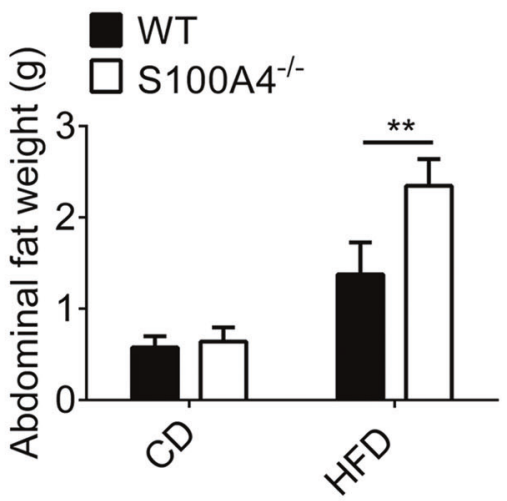

localized in SVF cells, but seldom in mature adipocytes (Fig. 1d). Compared with lean mice fed a normal CD, the level of S100A4 mRNA was decreased significantly in WAT from HFD-fed WT mice (Fig. 1e). Compared with WAT, S100A4 expression was very low in muscle and liver, and there were no obvious differences between CDWT mice and HFD-WT mice (Fig. 1f, g). Similar to S100A4 mRNA, the number of S100A4 ${ }^{+}$cells was also decreased in WAT in HFD-fed WT mice (Fig. 1h, i). These data demonstrated that S100A4 is mainly expressed on fibroblast and macrophage populations, but not on mature adipocytes in the WAT of mice, and the S100A4 expression level in adipose tissues was downregulated in HFD-fed WT mice.

\section{S100A4 deficiency aggravates HFD-induced obesity}

To confirm the role of S100A4 in the development of obesity, S100A4 $4^{-1-}$ mice and C57BL/6 (WT) control mice were fed an HFD or CD for 12 weeks. We observed that body weight gain was sharply increased in $\mathrm{S} 100 \mathrm{~A} 4^{-1-}$ mice compared with WT mice under HFD, while no changes were observed in mice on CD (Fig. 2a and Supplementary Table 2). Consistent with this, deletion of S100A4 increased abdominal fat weight (Fig. 2b). As illustrated in Fig. 2c, histological analysis revealed that $\mathrm{S} 100 \mathrm{~A} 4^{-1-}$ mice had massive fat vacuoles compared with WT mice. These results demonstrated that S100A4 deficiency aggravated the pathogenesis of HFD-induced obesity. 

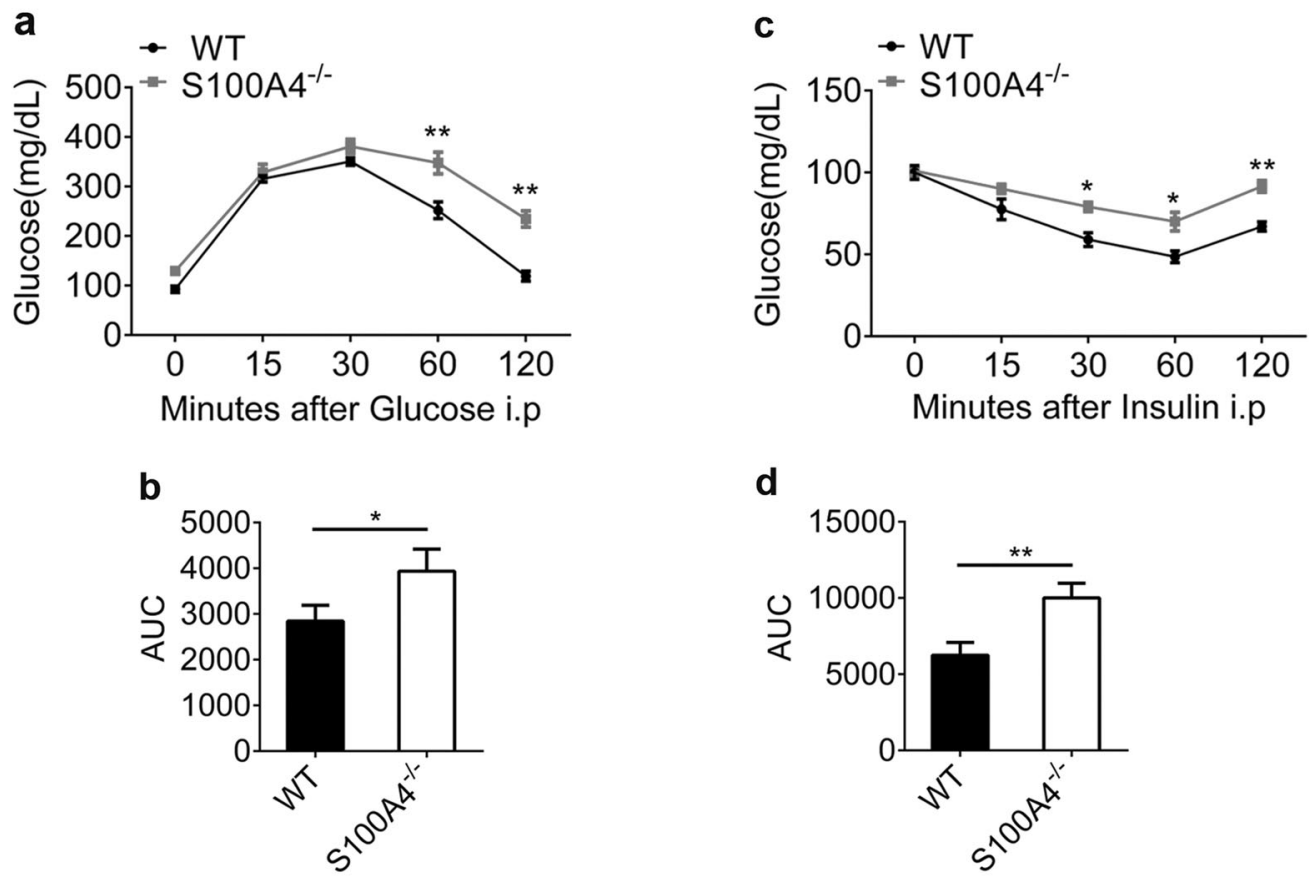

e

\section{WAT}
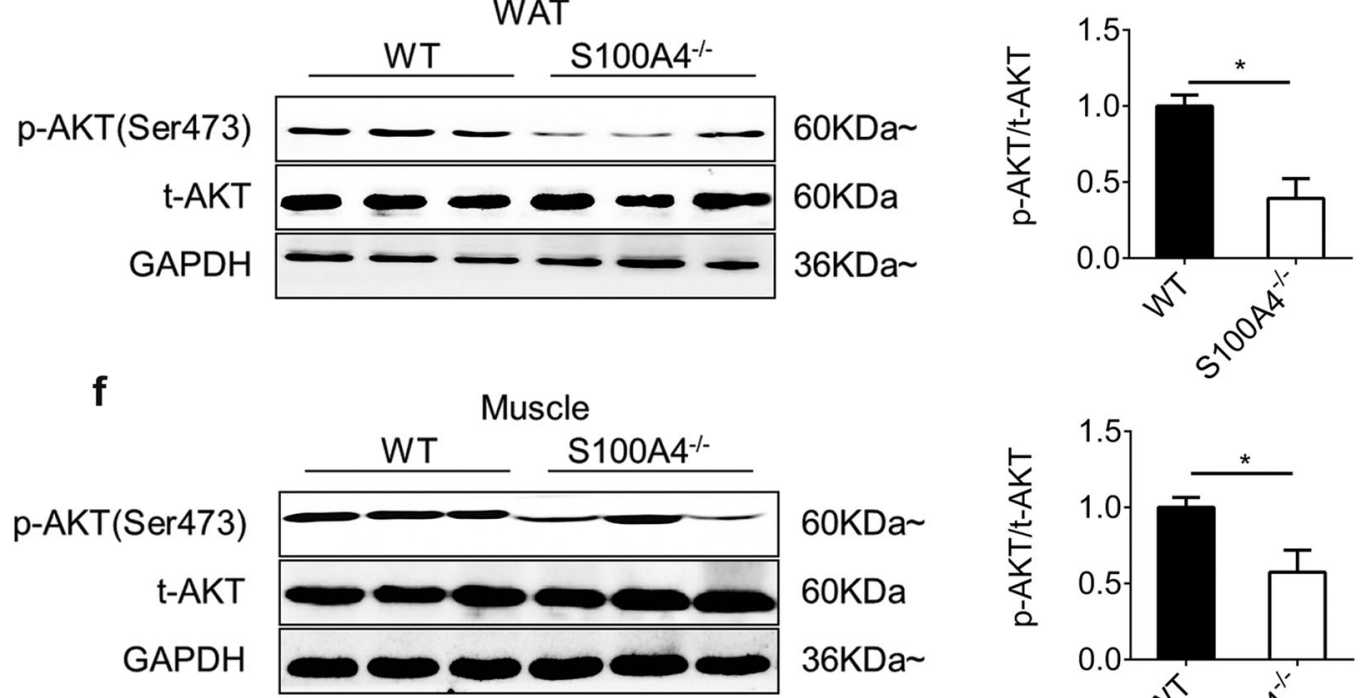

60KDa

$60 \mathrm{KDa}$

36KDa
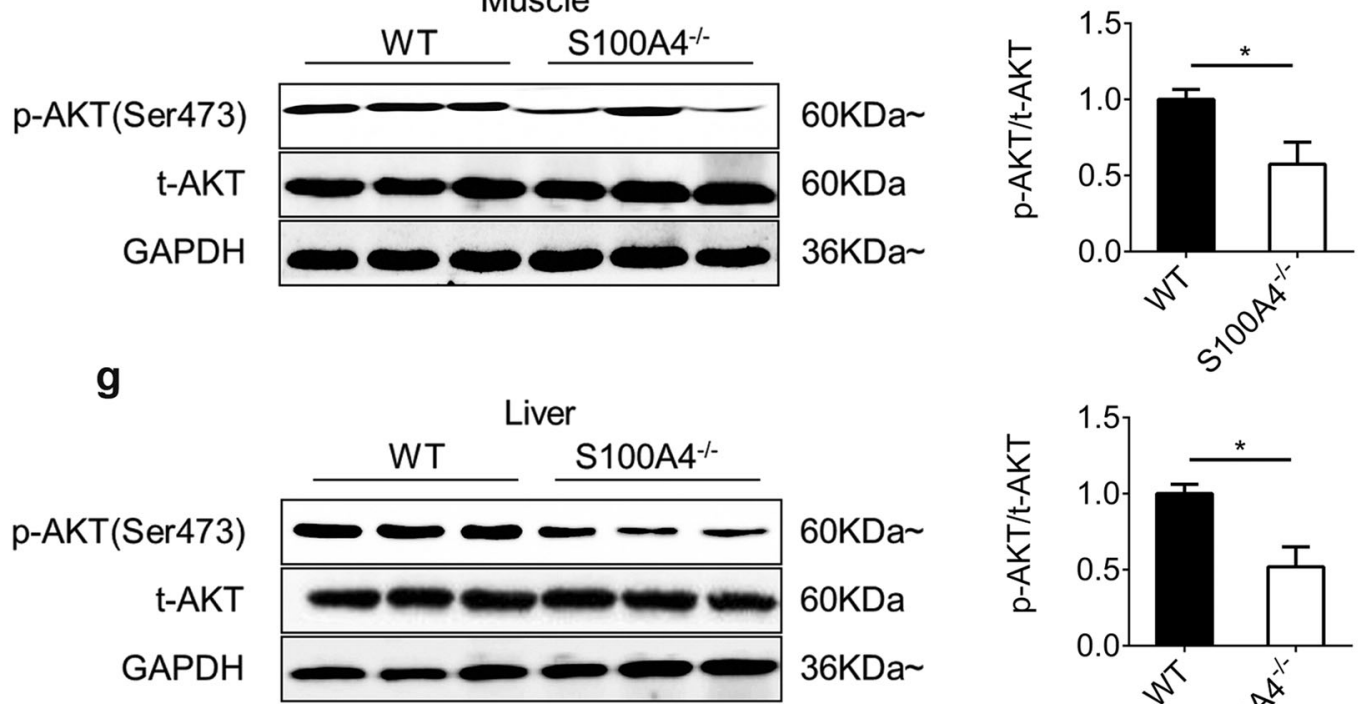

60KDa $60 \mathrm{KDa}$

36KDa

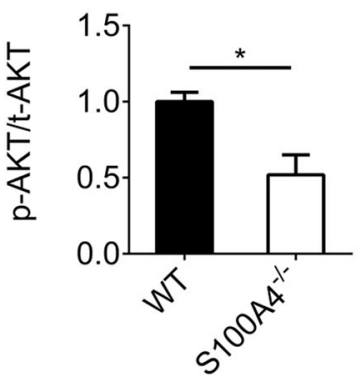

Fig. 3 S100A4 deficiency promotes insulin resistance and impairment of Akt pathway activation during HFD. a Glucose tolerance test (GTT) of WT versus S100A4 $4^{-l-}$ mice fed with HFD is shown $(n=5$ per group). b Area under the curve (AUC) shown in a. c Insulin resistance test (ITT) is shown ( $n=5$ per group). $\mathbf{d}$ Area under the curve (AUC) shown in c. e-g Western blot analysis of Akt and phospho-Akt (Ser473) in WATs, muscles and livers of mice after HFD. Quantification of relative phospho-Akt was assessed by Image $\mathrm{J}$. ${ }^{*} P<0.05$, $* * P<0.01$ 


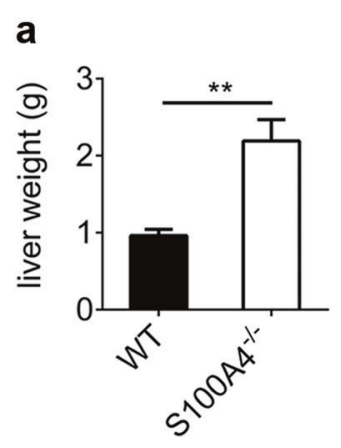

b

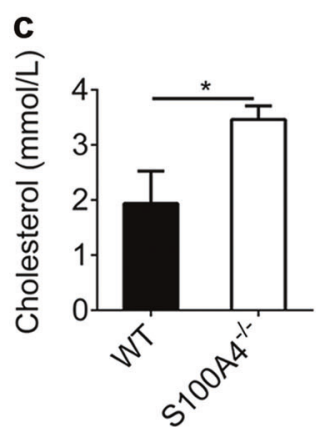

Oil red

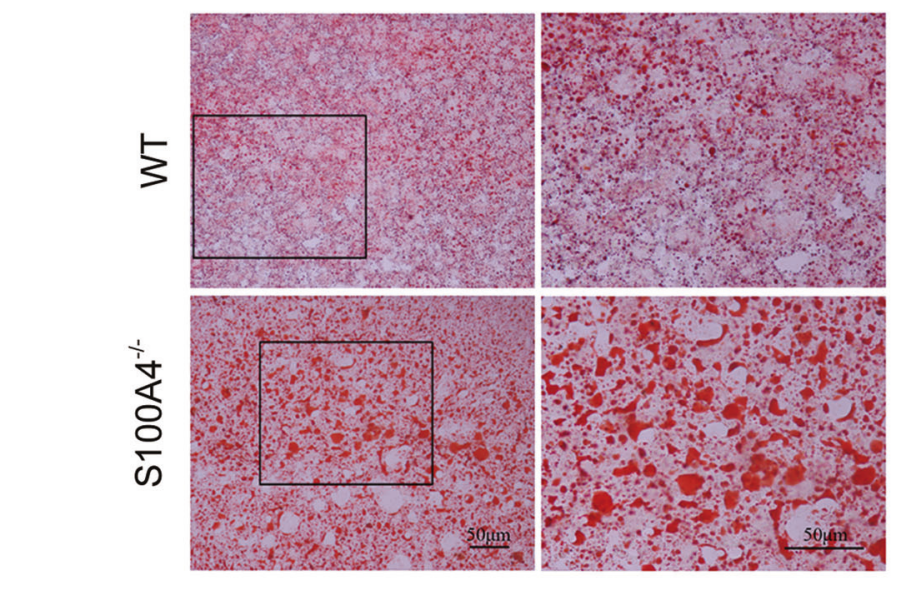

$\mathbf{f}$
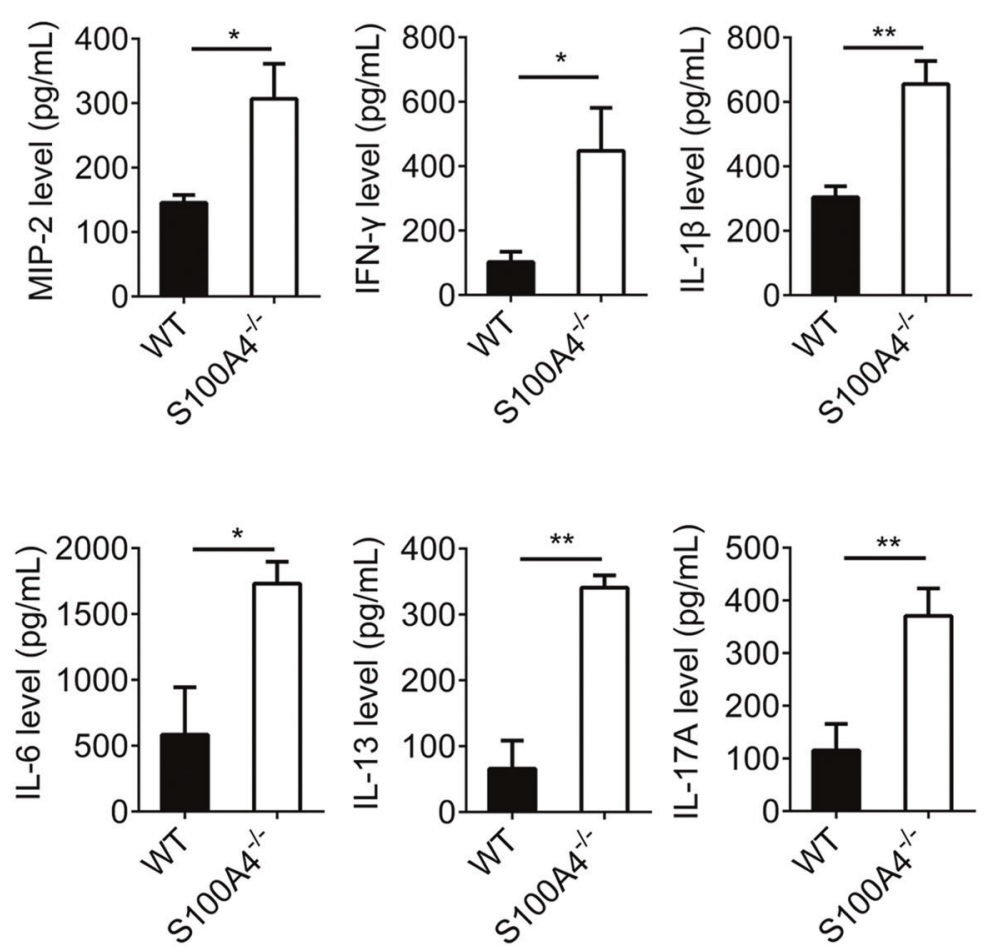

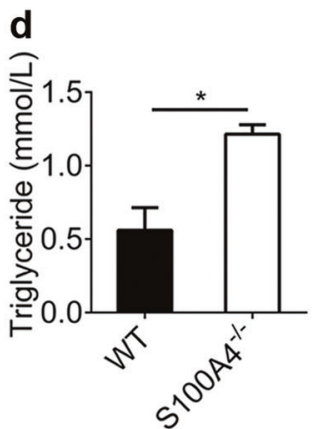

e

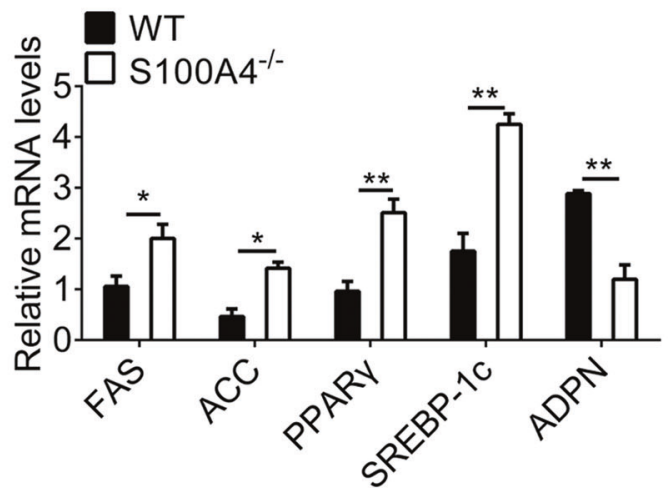

g
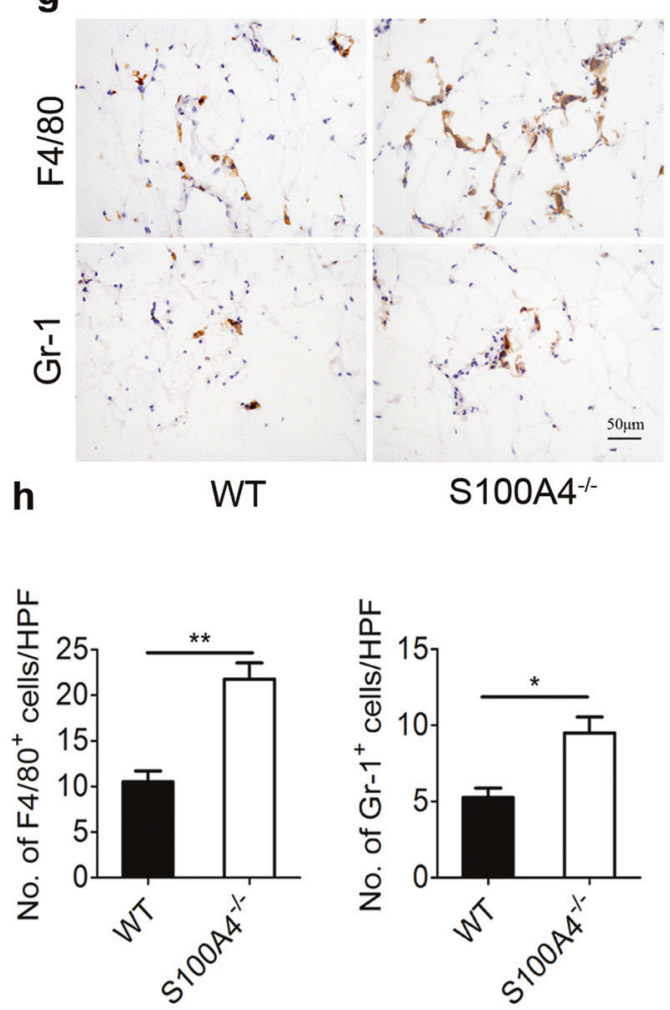
Fig. 4 S100A4 deficiency aggravates hepatic lipid accumulation and inflammation. a Liver weight of WT and S100A4 $4^{-1-}$ mice fed with HFD ( $n=5$ per group). b Oil Red O staining of liver sections from HFD-WT and HFD-S100A4 $4^{-1-}$ mice. Scale bar, $50 \mu \mathrm{m}$. c-d CHO and TG levels from WT and S100A4 ${ }^{-1-}$ mice in HFD were measured $(n=$ 5 per group). e qPCR analysis of lipogenic gene expression in livers from WT and S100A4 ${ }^{-1-}$ mice. f Levels of several inflammationrelated cytokines in livers from WT and S100A $4^{-/-}$mice. g F4/80 and Gr-1 staining of adipose tissue from WT and S100A4 $4^{-1-}$ mice. Scale bar, $50 \mu \mathrm{m}$. $\mathbf{h}$ The numbers of $\mathrm{F} 4 / 80^{+}$cells and Gr- $1^{+}$cells of HPF $(\times 200)$ from adipose tissue. $* P<0.05, * * P<0.01$

\section{S100A4 deficiency downregulates AKT pathway}

To preliminarily explore the effects of S100A4 on glucose intolerance and insulin sensitivity, mice were challenged with a GTT and ITT. On HFD, S100A4 $4^{-/-}$mice showed obviously increased glucose intolerance (Fig. 3a, b) and decreased insulin sensitivity (Fig. 3c, d), compared with WT mice.

Current investigations have revealed the relationship between the Akt pathway and insulin regulation during adipogenesis [29]. This pathway is typically inactivated during adipogenesis process, which is shown by decreased level of phosphorylated Akt (Ser473) [30]. Thus, we subsequently evaluated phosphorylation of Akt (Ser473) in WAT, skeletal muscles, and livers. As shown in Fig. 3e, S100A4 deficiency resulted in a significant downregulation in phosphorylated Akt levels in WATs. Consistent with this, there were relatively lower levels of activated Akt pathway in muscles, as well as the livers of HFD-S100A4 $4^{-l-}$ mice, compared with HFD-WT mice (Fig. 3f, g). Taken together, these data suggest that S100A4 constitutes a partial protection against the onset of obesity-associated disturbed insulin signaling.

\section{S100A4 deficiency aggravates hepatic lipid accumulation and inflammation}

Lipid accumulation in livers is often accompanied by elevated blood $\mathrm{CHO}$ and TG levels and highly related to the morbidity of obesity [31]. Indeed, S100A $4^{-l-}$ mice showed pronounced higher liver weight in HFD treatment compared with WT mice (Fig. 4a). Further, histological analysis displayed a higher lipid accumulation in the liver of S100A4 ${ }_{-1-}^{-}$mice (Fig. 4b). In line with this, $\mathrm{CHO}$ and TG were both significantly higher in HFD-S100A4 ${ }^{-/}$mice, compared with HFD-WT mice (Fig. 4c, d). To further explore the mechanisms underlying the high levels of $\mathrm{CHO}$ and TG observed in S100A4 ${ }^{--}$mice, we tested the abundance of transcription genes related to lipid biosynthesis and metabolism including fatty acid synthase (FAS), peroxisome proliferators activated receptor $\gamma(\operatorname{PPAR} \gamma)$, sterol regulatory element binding protein 1c (SREBP 1c), and adiponectin
(ADPN) in livers. We found that the levels of FAS, PPAR $\gamma$, and SREBP 1c were significantly increased, while ADPN was decreased in the livers of HFD-S100A4 $4^{-1-}$ mice compared to HFD-WT mice (Fig. 4e).

It is clear that an enhanced inflammatory response (which was characterized by an increased secretion of proinflammatory and chemokine factors) is a major driver of abnormal insulin pathway and metabolic syndrome in obesity [32]. We then assessed the levels of several inflammation cytokines, and found that the levels of inflammatory protein-2 (MIP-2), interferon- $\gamma$ (IFN- $\gamma$ ), interleukin-1 beta (IL-1 $\beta$ ), interleukin-6 (IL-6), interleukin13 (IL-13), and interleukin-17A (IL-17A) were much higher in the livers of HFD-S100A4 ${ }^{-1-}$ mice than that in HFD-WT mice (Fig. 4f). In addition, we also revealed that the numbers of infiltrated $\mathrm{F} 4 / 80^{+}$macrophages and $\mathrm{Gr}-1^{+}$neutrophils were also increased in WAT of HFD-S100A4 $4^{-1-}$ mice compared with HFD-WT mice (Fig. 4g, h). Therefore, these results indicated that S100A4 deficiency may contribute to impairing insulin signaling via modulating secretion of adipokines and inflammatory factors in HFDinduced obesity mice.

\section{Extracellular S100A4 improves Akt activation and inhibits inflammation in adipocytes}

We then used insulin to simulate the hyperinsulinic environment in obesity in 3T3-L1 adipocytes to explore the role of extracellular S100A4. Stimulation of these cells with S100A4 resulted in a significant increase of phosphorylated Akt (Ser473) levels (Fig. 5a, b). In addition, S100A4 administration downregulated transcription of lipogenesis genes and inflammatory factors in 3T3-L1 adipocytes (Fig. 5c, d). These results confirmed that extracellular S100A4 protein could attenuate insulin resistance while decreasing expression of lipogenesis genes and inflammatory genes in adipocytes.

\section{Overexpression of S100A4 leads to an increase Akt activation in adipocytes; whereas a siRNA mediated suppression of S100A4 decreases Akt activation}

Further, we detected the role of endogenous S100A4 in adipocytes in hyperinsulinic environment. We found that overexpression of S100A4 also increased insulin-induced Akt activation (Fig. 6a, b), and suppressed the mRNA levels of lipogenesis genes, as well as inflammatory factors in 3T3-L1 adipocytes (Fig. 6c, d). Such effects were also partially diminished in si-S100A4-treated 3T3-L1 cells (Fig. 7a-d). These data demonstrated that S100A4 promoted Akt activation through inhibiting lipogenesis and inflammation in 3T3-L1 adipocytes. 
Fig. 5 Effects of extracellular S100A4 on the expression of Akt in 3T3-L1 adipocytes. Insulin signaling was quantified by phosphorylation of the downstream effector Akt. a S100A4 (1 ug/ml) treatment for $4 \mathrm{~h}$ activated the Akt signaling pathway in 3T3-L1 adipocytes. b Quantification of relative phospho-Akt by Image J. c qPCR analysis of lipogenic gene expression in 3T3-L1 cells. d Relative mRNA expression of inflammatory genes in 3T3-L1 cells. $* P<0.05, * * P<0.01$
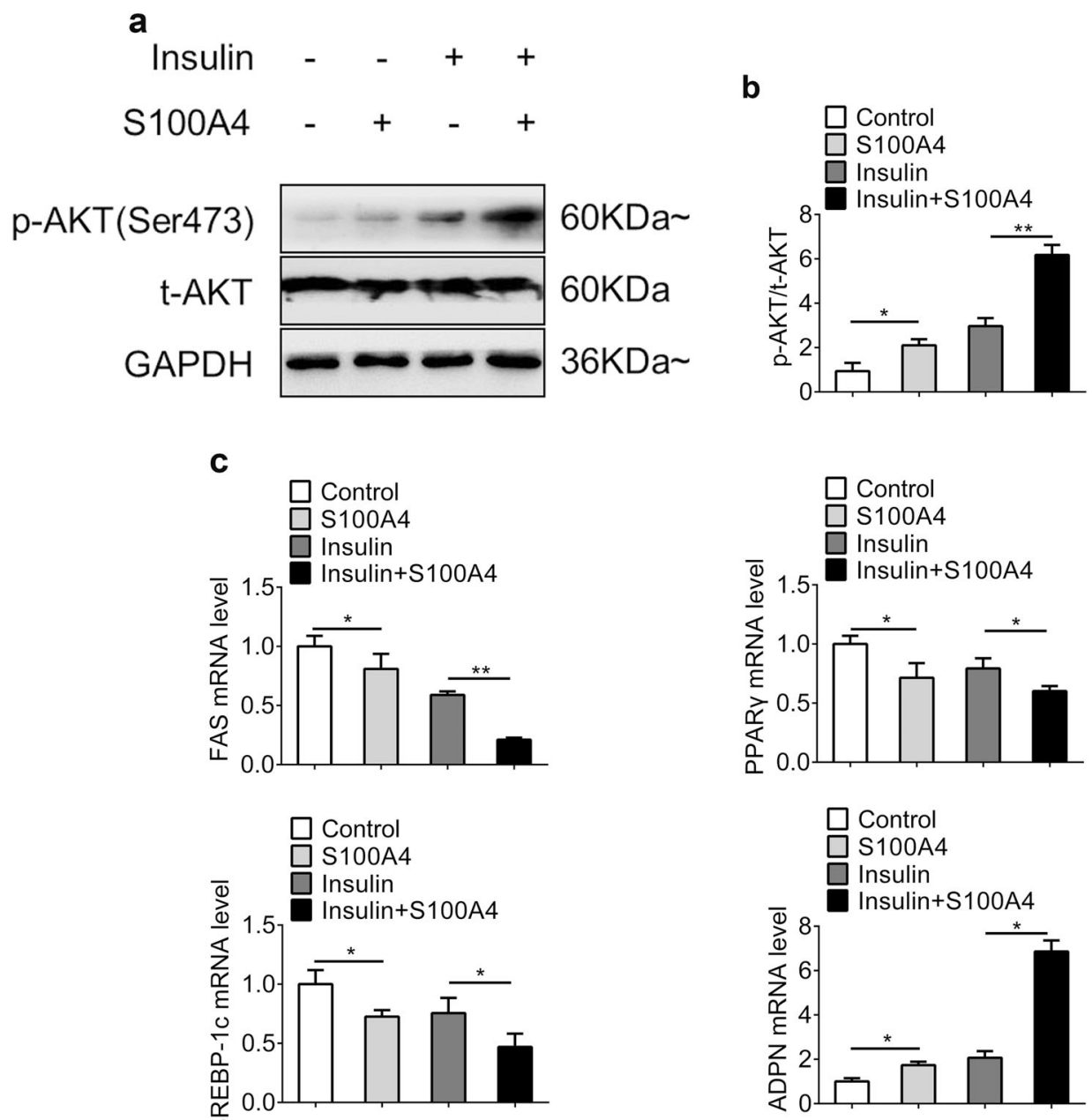

d
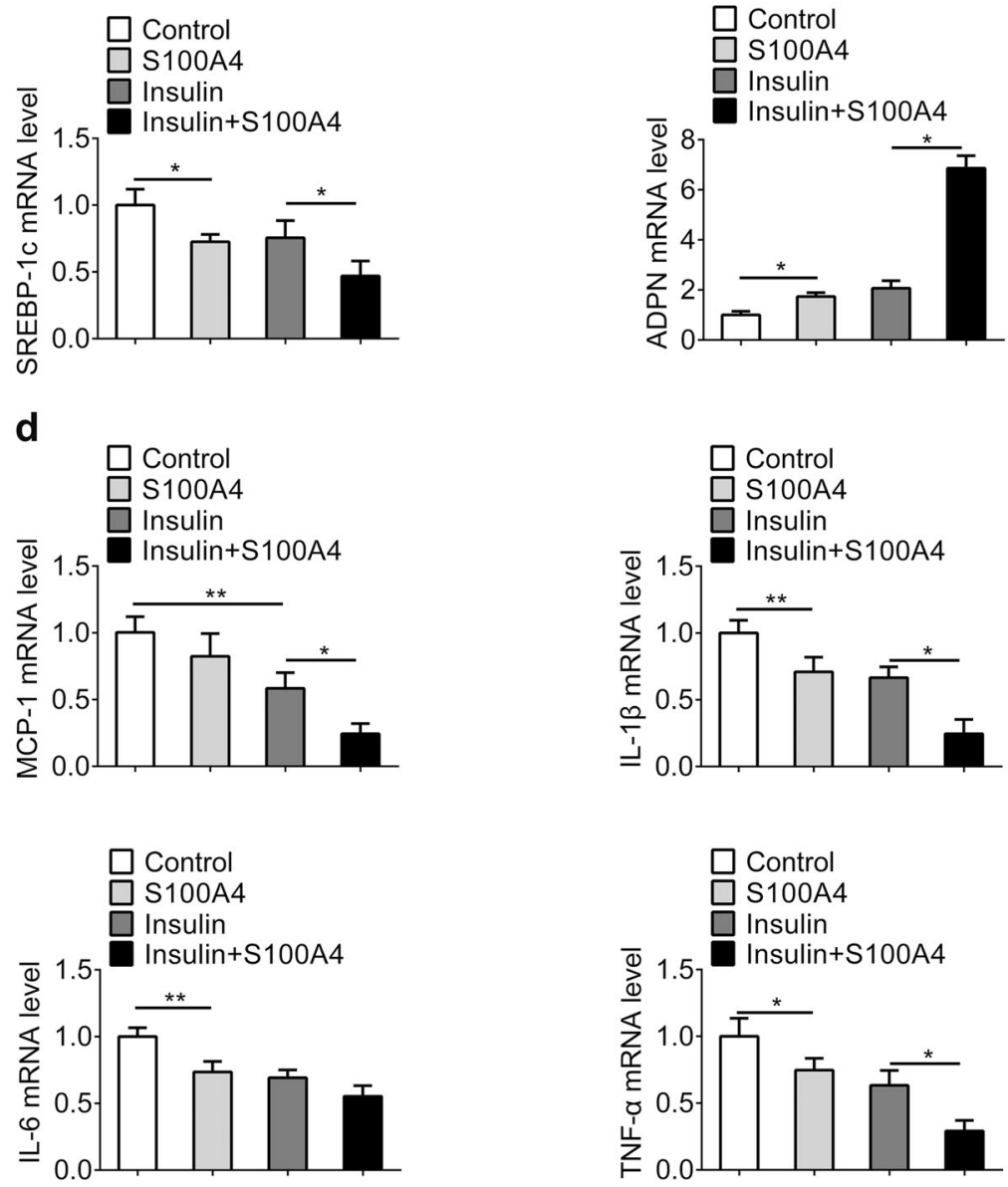
Fig. 6 Effects of overexpressed S100A4 on the expression of Akt in 3T3-L1 adipocytes. a 3T3-L1 cells were transfected with either a plasmid overexpressing S100A4 (pEGFP-S100A4) or a control plasmid (pEGFP). Insulin signaling was quantified by phosphorylation of the downstream effector Akt. b Quantification of relative phospho-Akt by Image J. c qPCR analysis of lipogenic gene expression. d Relative mRNA expression of inflammatory genes. $* P<0.05, * * P<0.01$

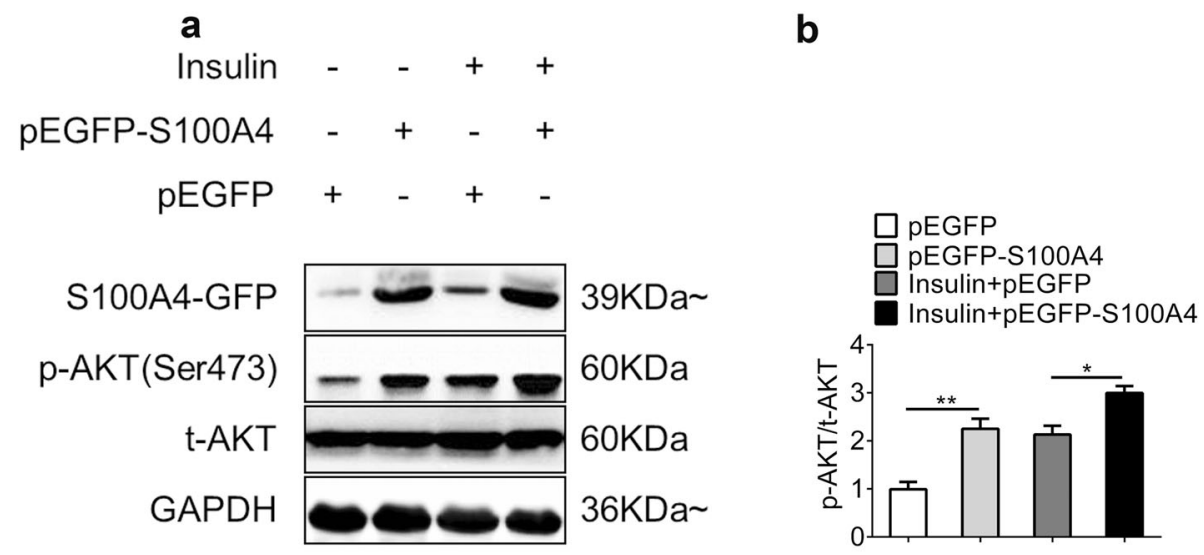

C

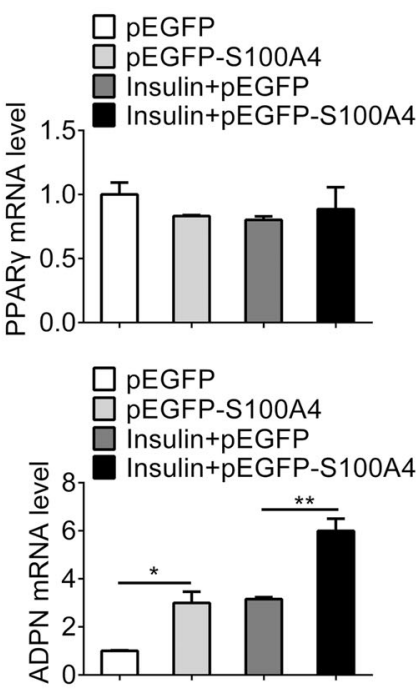

d
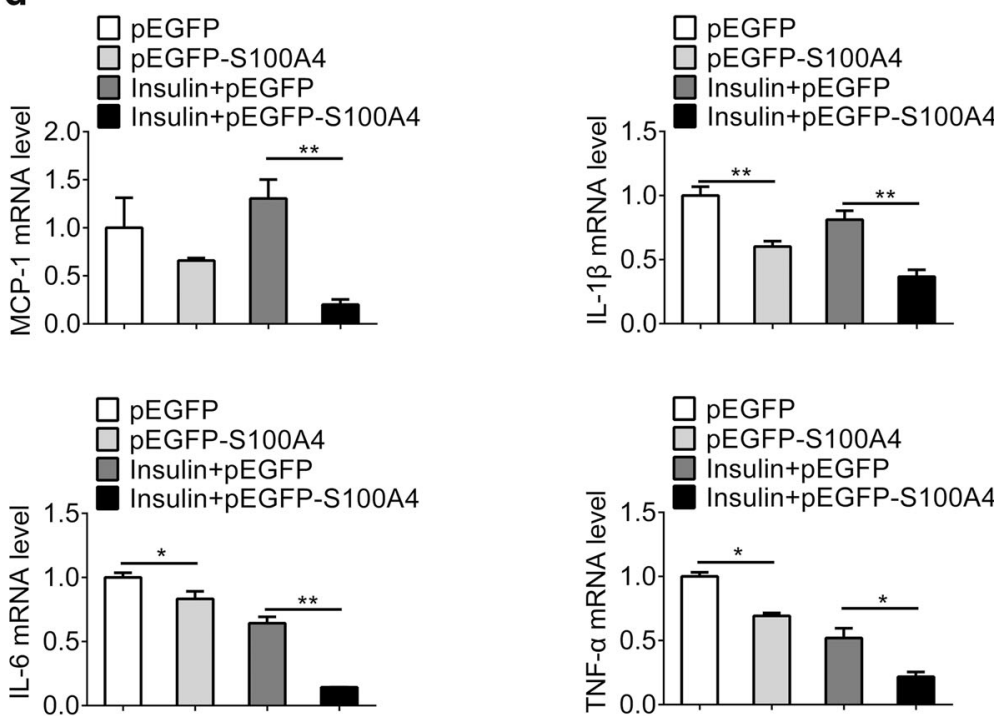
Fig. 7 Effects of silenced S100A4 on the expression of Akt in 3T3-L1 adipocytes. Endogenous S100A4 in 3T3-L1 was silenced using siRNA approach. a The expression of phospho-Akt in 3T3-L1 adipocytes was measured by western blot. b Quantification of relative phospho-Akt by Image J. c qPCR analysis of lipogenic gene expression. d Relative mRNA expression of inflammatory genes. $* P<0.05$, $* * P<0.01$ a

b
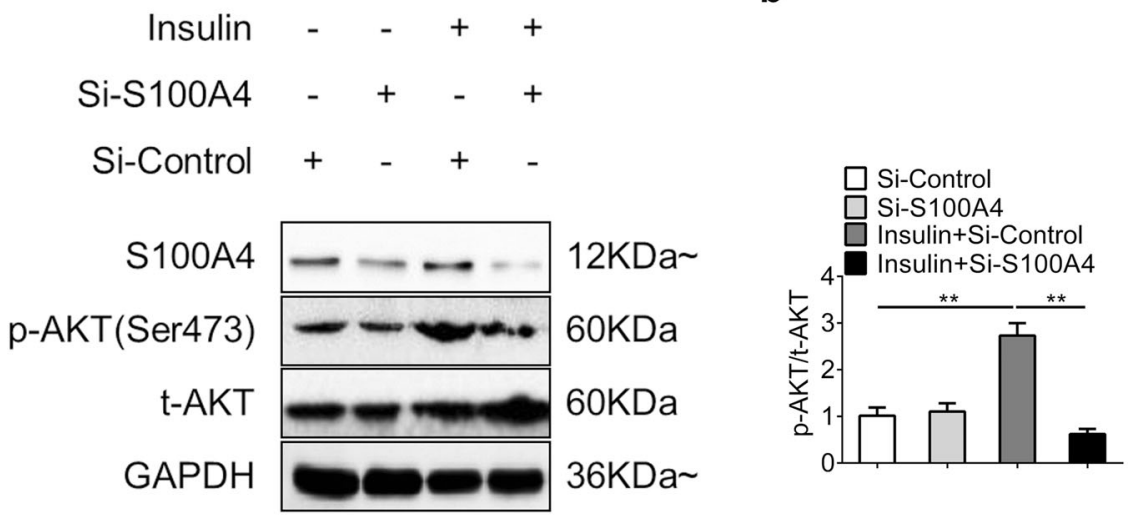

C
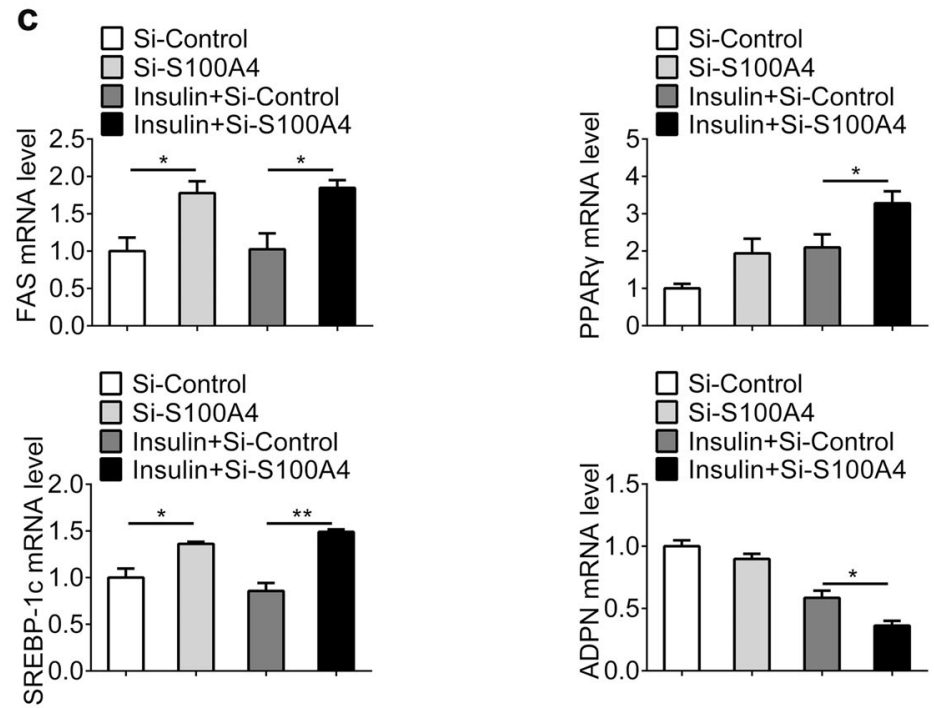

d
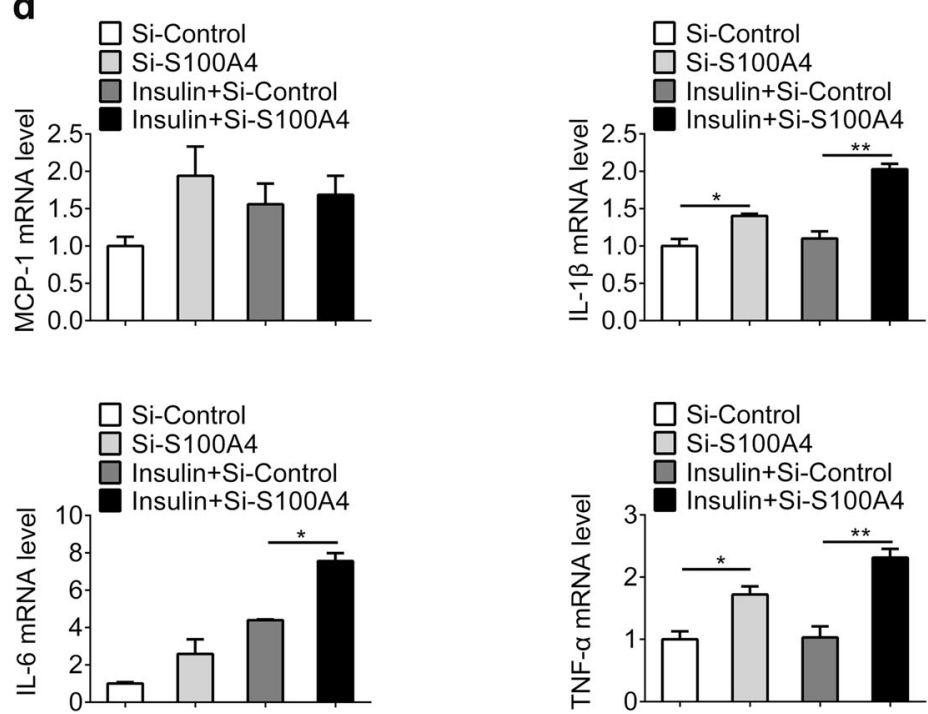


\section{Discussion}

In this study, we demonstrated that S100A4 alleviated obesity and promotes insulin signaling activation in HFD administration. S100A4 was mainly expressed by fibroblasts and macrophages in adipose tissue, and it was downregulated in HFD-fed WT mice. HFD-induced weight gain, and insulin pathway was inactivated in S100A4 deficient mice. Hepatic lipid accumulation and inflammation were also aggravated in S100A4 ${ }^{-/-}$mice. Furthermore, extracellular S100A4 protein, as well as high-expressed intracellular S100A4 promoted insulin-related Akt activation in adipocytes and depressed transcription of fat formation-related genes, as well as proinflammatory genes.

S100A4 plays important roles in many physiological functions, such as cell motility, adhesion, proliferation, invasion, and metastasis [14, 33-35]. Intracellularly, S100A4 binds to several targets, regulating cytoskeletal dynamics and cell motility and proliferation [36]. Moreover, S100A4 is secreted from both tumor and nonmalignant cells and exerts extracellular effects regulating angiogenesis, cell migration and inflammation [33, 37, 38]. However, its role in obesity development, insulin signaling and obesityrelated inflammation has not been well established. It has been reported that certain members of the $\mathrm{S} 100$ family have obesity-facilitating properties. S100B promoted obesity by impairing insulin sensitivity and overexpression of S100A16 can enhance adipogenesis in 3T3-L1 preadipocytes [39, 40]. However, S100A4 seems to play a protective role during obesity in our study. Our results demonstrated that S100A4 deficient mice showed severe symptoms during HFD-induced obesity, and both intracellular and extracellular S100A4 could promote activating Akt signaling in 3T3-L1 adipocytes. Because S100A4 is a small molecular protein, we conjecture that S100A4 inhibits obesity development via collaborating with other intracellular proteins or transcription factors. On this point, S100A4 has been reported to affect various protein kinases, especially Akt, which is not only a well-recognized tumor modulator but also an adipogenesis regulator [41, 42]. This study displayed that S100A4 stimulates activation of the Akt pathway (the key insulin-related pathway) during HFDinduced obesity. Thus, regulating the expression of S100A4 may obviously influence insulin sensitivity in adipocytes through insulin-mediated glucose disposal or insulin signaling.

Former observations have reported that inhibiting several regulators (including FAS, SREBP-1C) hinders liver lipid deposition in obesity and its associated symptoms [43-45]. In this study, we found that S100A4 deficiency caused elevated accumulation of liver fat, and that led to elevated CHO and TG (Fig. 4c, d). Consistent with this, the data obtained from 3T3-L1 adipocytes verified the presupposition that S100A4 works as a new adipogenesisinhibitor, which downregulates transcriptional activities of the regulators mentioned above. In addition, many studies have demonstrated that obesity-induced inflammation plays a critical role in the generation of metabolic syndromes, including a dysfunctional glucose metabolism and insulin pathway [46, 47]. A number of inflammatory cytokines have been extensively shown to play critical roles in obesity-related inflammation and insulin resistance, including IL-1 $\beta$, IL-6, and IL-17A [48, 49]. In this study, we found that cytokine MIP-2, IFN- $\gamma$, IL-1 $\beta$, IL-6, IL-13, and IL-17A levels were significantly increased in the livers of HFD-S100A4 ${ }^{-1-}$ mice than that in HFD-WT mice (Fig. 4f), while the infiltration of $\mathrm{F} 4 / 80^{+}$macrophages and $\mathrm{Gr}-1^{+}$neutrophils in adipose tissue were also aggravated in HFD-S100A4 $4^{-1-}$ group (Fig. 4g, h), suggesting that S100A4 inhibited inflammation in the HFD model. However, it has also been reported that S100A4 induced a network of inflammatory cytokines or promoted inflammatory response of mononuclear cells in other models [50]. Thus, the inflammation regulatory function of S100A4 may be different under various conditions, and the related mechanisms need further study.

S100A4 expression was initially characterized in the cells of mesenchymal origin, including stromal fibroblasts and epithelial cells undergoing epithelial-mesenchymal transition [51]. Recently, it was found that $\mathrm{S} 100 \mathrm{~A} 4^{+}$cells in the liver were a subtype of macrophages [15]. However, it seems that S100A4 is expressed in different types of cells in various tissues. The cellular origin of S100A4 in the adipose tissues is not clear. We found many stromal cells expressed S100A4 in adipose tissues from HFDinduced obesity mice. Of the $\mathrm{S} 100 \mathrm{~A} 4^{+}$cells, approximately $63.3 \%$ were $\mathrm{SMA}^{+}$fibroblasts and $33.8 \%$ were $\mathrm{F} 4 / 80^{+}$macrophages. However, the role of the different types of $\mathrm{S} 100 \mathrm{~A} 4^{+}$cells in adipose tissues microenvironment and obesity still needs further elucidation.

Receptor for advanced glycation end products (RAGE), a pattern recognition receptor, is a well-established interaction partner for S100A4 [52]. RAGE has been recently reported to be associated with AGE-deteriorating action in diabetes, as well as obesity in nondiabetic animals [53, 54]. In this study, we analyzed whether the S100A4 induced insulin signaling activation in 3T3-L1 adipocytes were RAGE-dependent. The RAGE-specific inhibitor FPS-ZM1 was administered to 3T3-L1 cells. However, RAGE inhibition by FPS-ZM1 in 3T3-L1 cells did not result in the abolishment of the promotion effect of S100A4 on Akt activation (data not shown). The receptor of S100A4 in obesity development needs further study.

In conclusion, our results demonstrate that S100A4 inhibits adipogenesis by activating the Akt pathway and reducing inflammation factors. Lack of S100A4 promoted 
HFD-induced obesity, hepatic lipid accumulation and inflammation. This study reveals an interesting linkage between S100A4, insulin signaling (Akt pathway) and inflammation during obesity development. S100A4 may provide a promising target for adiposity prevention and treatment.

Acknowledgements This work was supported by the National Natural Science Foundation of China (81370543 and 81772497).

\section{Compliance with ethical standards}

Conflict of interest The authors declare that they have no conflict of interest.

\section{References}

1. Ng M, Fleming $\mathrm{T}$, Robinson $\mathrm{M}$, et al. Global, regional, and national prevalence of overweight and obesity in children and adults during 1980-2013: a systematic analysis for the Global Burden of Disease Study 2013. Lancet. 2014;384:766-81.

2. Richard D. Cognitive and autonomic determinants of energy homeostasis in obesity. Nat Rev Endocrinol. 2015;11:489-501.

3. Gosby AK, Conigrave AD, Raubenheimer D, et al. Protein leverage and energy intake. Obes Rev. 2014;15:183-91.

4. Hossain P, Kawar B, El Nahas M. Obesity and diabetes in the developing world--a growing challenge. $N$ Engl $J$ Med. 2007;356:213-5.

5. Kahn SE, Hull RL, Utzschneider KM. Mechanisms linking obesity to insulin resistance and type 2 diabetes. Nature. 2006;444:840-6.

6. Samuel VT, Petersen KF, Shulman GI. Lipid-induced insulin resistance: unravelling the mechanism. Lancet. 2010;375:2267-77.

7. Romeo GR, Lee J, Shoelson SE. Metabolic syndrome, insulin resistance, and roles of inflammation--mechanisms and therapeutic targets. Arterioscler Thromb Vasc Biol. 2012;32:1771-6.

8. Chen S, Zhang W, Tang C, et al. Vanin-1 is a key activator for hepatic gluconeogenesis. Diabetes. 2014;63:2073-85.

9. Cotter DG, Ercal B, Huang X, et al. Ketogenesis prevents dietinduced fatty liver injury and hyperglycemia. J Clin Invest. 2014;124:5175-90.

10. Lumeng CN, Saltiel AR. Inflammatory links between obesity and metabolic disease. J Clin Invest. 2011;121:2111-7.

11. Tateishi K, Okada Y, Kallin EM, et al. Role of Jhdm2a in regulating metabolic gene expression and obesity resistance. Nature. 2009;458:757-61.

12. Greco M, Chiefari E. Early effects of a hypocaloric, Mediterranean diet on laboratory parameters in obese individuals. Mediat Inflamm. 2014;2014:750860.

13. Strutz F, Okada H, Lo CW, et al. Identification and characterization of a fibroblast marker: FSP1. J Cell Biol. 1995;130:393-405.

14. Boye K, Maelandsmo GM. S100A4 and metastasis: a small actor playing many roles. Am J Pathol. 2010;176:528-35.

15. Osterreicher $\mathrm{CH}$, Penz-Osterreicher M, Grivennikov SI, et al. Fibroblast-specific protein 1 identifies an inflammatory subpopulation of macrophages in the liver. Proc Natl Acad Sci USA. 2011;108:308-13.

16. Chen L, Li J, Zhang J, et al. S100A4 promotes liver fibrosis via activation of hepatic stellate cells. J Hepatol. 2015;62:156-64.

17. Zhang J, Chen L, Xiao M, et al. FSP1+ fibroblasts promote skin carcinogenesis by maintaining MCP-1-mediated macrophage infiltration and chronic inflammation. Am $\mathrm{J}$ Pathol. 2011;178:382-90.

18. Dmytriyeva O, Pankratova S, Owczarek S, et al. The metastasispromoting S100A4 protein confers neuroprotection in brain injury. Nat Commun. 2012;3:1197.

19. Fabris L, Cadamuro M, Moserle L, et al. Nuclear expression of S100A4 calcium-binding protein increases cholangiocarcinoma invasiveness and metastasization. Hepatology. 2011;54:890-9.

20. Zhang J, Chen L, Liu X, et al. Fibroblast-specific protein 1/ S100A4-positive cells prevent carcinoma through collagen production and encapsulation of carcinogens. Cancer Res. 2013;73:2770-81.

21. Schmidt-Hansen B, Klingelhofer J, Grum-Schwensen B, et al. Functional significance of metastasis-inducing S100A4(Mts1) in tumor-stroma interplay. J Biol Chem. 2004;279:24498-504.

22. Yan XL, Jia YL, Chen L, et al. Hepatocellular carcinomaassociated mesenchymal stem cells promote hepatocarcinoma progression: role of the S100A4-miR155-SOCS1-MMP9 axis. Hepatology. 2013;57:2274-86.

23. Li ZH, Dulyaninova NG, House RP, et al. S100A4 regulates macrophage chemotaxis. Mol Biol Cell. 2010;21:2598-610.

24. Brisslert M, Bian L, Svensson MN, et al. S100A4 regulates the Src-tyrosine kinase dependent differentiation of Th17 cells in rheumatoid arthritis. Biochim Biophys Acta. 2014;1842:2049-59.

25. Fei F, Qu J, Zhang M, et al. S100A4 in cancer progression and metastasis: asystematic review. Oncotarget. 2017;8:73219-39.

26. Morselli E, Criollo A, Rodriguez-Navas C, et al. Chronic high fat diet consumption impairs metabolic health of male mice. Inflamm Cell Signal. 2014;1:e561.

27. Heydemann A. An overview of murine high fat diet as a model for type 2 diabetes mellitus. J Diabetes Res. 2016;2016:2902351.

28. Chang SK, Kohlgruber AC, Mizoguchi F, et al. Stromal cell cadherin-11 regulates adipose tissue inflammation and diabetes. $\mathrm{J}$ Clin Invest. 2017;127:3300-12.

29. Jordan SD, Kruger M, Willmes DM, et al. Obesity-induced overexpression of miRNA-143 inhibits insulin-stimulated AKT activation and impairs glucose metabolism. Nat Cell Biol. 2011;13:434-46.

30. Bezy O, Tran TT, Pihlajamaki J, et al. PKCdelta regulates hepatic insulin sensitivity and hepatosteatosis in mice and humans. J Clin Invest. 2011;121:2504-17.

31. Cohen JC, Horton JD, Hobbs HH. Human fatty liver disease: old questions and new insights. Science. 2011;332:1519-23.

32. Ballak DB, van Diepen JA, Moschen AR, et al. IL-37 protects against obesity-induced inflammation and insulin resistance. Nat Commun. 2014;5:4711.

33. O'Connell JT, Sugimoto H, Cooke VG, et al. VEGF-A and Tenascin-C produced by S100A4+ stromal cells are important for metastatic colonization. Proc Natl Acad Sci USA. 2011;108:16002-7.

34. Grum-Schwensen B, Klingelhofer J, Beck M, et al. S100A4neutralizing antibody suppresses spontaneous tumor progression, pre-metastatic niche formation and alters T-cell polarization balance. BMC Cancer. 2015;15:44.

35. Roh J, Knight S, Chung JY, et al. S100A4 expression is a prognostic indicator in small intestine adenocarcinoma. J Clin Pathol. 2014;67:216-21.

36. Tarabykina S, Griffiths TR, Tulchinsky E, et al. Metastasisassociated protein S100A4: spotlight on its role in cell migration. Curr Cancer Drug Targets. 2007;7:217-28.

37. Cabezon T, Celis JE, Skibshoj I, et al. Expression of S100A4 by a variety of cell types present in the tumor microenvironment of human breast cancer. Int J Cancer. 2007;121:1433-44.

38. Dahlmann M, Kobelt D, Walther W, et al. S100A4 in cancer metastasis: Wnt signaling-driven interventions for metastasis restriction. Cancers 2016;8:59-80. 
39. Fujiya A, Nagasaki H, Seino Y, et al. The role of S100B in the interaction between adipocytes and macrophages. Obesity. 2014;22:371-9.

40. Liu Y, Zhang R, Xin J, et al. Identification of S100A16 as a novel adipogenesis promoting factor in 3T3-L1 cells. Endocrinology. 2011;152:903-11.

41. Yang W, Nam K, Ju JH, et al. S100A4 negatively regulates betacatenin by inducing the Egr-1-PTEN-Akt-GSK3beta degradation pathway. Cell Signal. 2014;26:2096-106.

42. Xie X, Man X, Zhu Z, et al. Tumor suppressor RIZ1 in obesity and the PI3K/AKT/mTOR pathway. Obesity. 2016;24:389-97.

43. Haas JT, Miao J, Chanda D, et al. Hepatic insulin signaling is required for obesity-dependent expression of SREBP-1c mRNA but not for feeding-dependent expression. Cell Metab. 2012;15:873-84.

44. Wu X, Romero D, Swiatek WI, et al. PAS kinase drives lipogenesis through SREBP-1 maturation. Cell Rep. 2014;8:242-55.

45. Lisi S, Gamucci O, Vottari T, et al. Obesity-associated hepatosteatosis and impairment of glucose homeostasis are attenuated by haptoglobin deficiency. Diabetes. 2011;60:2496-505.

46. Gregor MF, Hotamisligil GS. Inflammatory mechanisms in obesity. Annu Rev Immunol. 2011;29:415-45.

47. Glass CK, Olefsky JM. Inflammation and lipid signaling in the etiology of insulin resistance. Cell Metab. 2012;15:635-45.
48. Finucane OM, Lyons CL, Murphy AM, et al. Monounsaturated fatty acid-enriched high-fat diets impede adipose NLRP3 inflammasome-mediated IL-1beta secretion and insulin resistance despite obesity. Diabetes. 2015;64:2116-28.

49. Cox AJ, West NP, Cripps AW. Obesity, inflammation, and the gut microbiota. Lancet Diabetes Endocrinol. 2015;3:207-15.

50. Hansen MT, Forst B, Cremers N, et al. A link between inflammation and metastasis: serum amyloid $\mathrm{A} 1$ and $\mathrm{A} 3$ induce metastasis, and are targets of metastasis-inducing S100A4. Oncogene. 2015;34:424-35.

51. Schneider M, Hansen JL, Sheikh SP. S100A4: a common mediator of epithelial-mesenchymal transition, fibrosis and regeneration in diseases? J Mol Med. 2008;86:507-22.

52. Chaabane C, Heizmann CW, Bochaton-Piallat ML. Extracellular S100A4 induces smooth muscle cell phenotypic transition mediated by RAGE. Biochim Biophys Acta. 2015;1853:2144-57.

53. Cheng HS, Ton SH, Tan JBL, et al. The ameliorative effects of a tocotrienol-rich fraction on the AGE-RAGE axis and hypertension in high-fat-diet-fed rats with metabolic syndrome. Nutrients 2017;9:984-1001.

54. Subramanian S, Pallati PK, Sharma P, et al. Significant association of TREM-1 with HMGB1, TLRs and RAGE in the pathogenesis of insulin resistance in obese diabetic populations. Am J Transl Res. 2017;9:3224-44. 